\title{
ASPECTOS GEOMORFOLÓGICOS DO MUNICÍPIO DE SÃO JOSÉ DOS CAMPOS (SP): ÊNFASE NA ÁREA URBANA
}

Paulo Sérgio de Rezende Nascimento - Engenheiro Geólogo, Prof. Dr. do Centro de Ensino Superior de Primavera - CESPRI

Rua Diamantina S/N, Quadra 132, Primavera (Rosana-SP) 19.274-000

$$
\text { psrn@zipmail.com.br }
$$

\section{RESUMO}

Como elemento síntese da paisagem, o relevo é um dos aspectos fisiográficos mais dinâmico da paisagem, resultado da ação do clima, da geologia e da ação antrópica. Assim, o presente trabalho teve como objetivo a caracterização morfográfica dos domínios geomorfológicos do município de São José dos Campos (SP) visando descrever o relevo, o qual foi um dos fatores preponderante no surgimento deste município e que condicionou o crescimento da sua malha urbana. Assim, até os dias atuais, é notória a concentração urbana nos relevos compostos pelos terraços modernos e colinas suavizadas.

Palavras-chave: Domínio geomorfológico, relevo, área urbana.

\begin{abstract}
As an element synthesis of the landscape, the relief is the environment physiografic aspect more dynamic, which one is the result of interaction among climate, geology and human action. Thus, the present work had as objective the morphographic characterization of the geomorphologycal domain of the São José dos Campos (SP) city, that aims to describe the relief, which was one of the preponderant factors in sprouting of this city and conditioned the growth of its urban area. Nowadays is well known, that there is an urban concentration in relives represented by the modern terraces and smoothed hills.
\end{abstract}

Key-words: Geomorphologycal domain, relief, urban area

\section{Introdução}

Muitos ramos de pesquisa alegam ser o relevo, a base essencial na qual se assenta a ocupação humana na superfície da Terra e por isso é um dos condicionantes fisiográficos que determinam o crescimento urbano. Assim, é importante ter um conhecimento adequado da morfologia da área e a necessidade de se estabelecer um controle para o processo de desenvolvimento urbano, na medida em que esse, ao ocorrer de forma não ordenada, tende a 
comprometer o desenvolvimento econômico-ambiental em âmbito regional, nacional, e mesmo global (OLIVEIRA, 1997).

A geomorfologia é o ramo do conhecimento científico que se propõe a descrever e classificar o modelado terrestre e explicar os processos que lhe deram origem. Com o surgimento do sensoriamento remoto, os pesquisadores incorporaram esta ferramenta aos seus estudos, não sendo os geomorfólogos a exceção. O fenômeno geomorfológico é de extensão espacial muito favorável, podendo ser observado quer a nível orbital quer a nível microscópio. À medida que aumenta a extensão espacial de uma forma, ou de um conjunto de formas, mais difícil se torna ao observador estudá-la em sua totalidade. Neste sentido, a integração da geomorfologia e do estudo da expansão urbana com o sensoriamento remoto é de importância fundamental para o fornecimento de produtos confiáveis.

A morfologia das paisagens do sudeste do Brasil foi considerada como reflexo das mudanças climáticas ocorridas durante o Quaternário. No entanto, mais do que a alternância de diferentes períodos climáticos, o modelado do relevo resultou da atuação combinada do clima e de impulsos de energia desencadeados por atividades tectônicas (FLORENZANO, 1993).

A geomorfologia atual do município de São José dos Campos, área de estudo deste trabalho, está intimamente condicionada à tectônica (morfoestrutura) e foi esculpida por processos erosivos e de agradação (morfoescultura). A malha urbana de São José dos Campos está concentrada em uma superfície muito rebaixada em relação ao limite total do município. Assim, a morfografia determinou o desenvolvimento urbano, a qual se concentrou, inicialmente, nas áreas planas e suavizadas dos terraços e das colinas. No entanto, o avanço acelerado deste crescimento urbano tem causado problemas estruturais do espaço urbano, como a utilização de encostas e várzeas para fins de urbanização.

Desta forma, o objetivo deste trabalho foi mapear as formas de relevo em domínios geomorfológicos visando delimitar os compartimentos de relevo que determinaram as áreas iniciais do surgimento e crescimento da área urbana de São José dos Campos, para servir de subsídio às estratégias de controle do uso da terra urbana e para a atualização da lei de zoneamento e parcelamento do solo para atender as situações emergentes.

Evolução geológica do Vale do Paraíba e da Bacia Sedimentar de Taubaté

Para se entender a gênese e as características das feições morfológicas do município de São José dos Campos é necessário conhecer a evolução e o arcabouço geológico do Vale do Paraíba e da Bacia de Taubaté. 


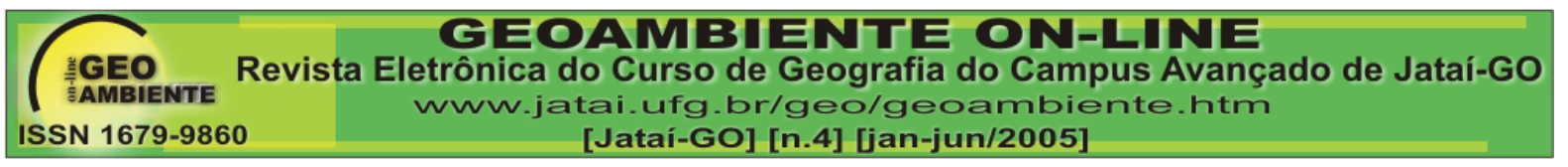

O Vale do Paraíba caracteriza-se por uma superfície muito rebaixada embutida em rochas Pré-Cambrianas, limitada pelas serras da Mantiqueira a nordeste e do Mar a sudeste. No Pré-Cambriano (Ciclo Brasiliano), a movimentação tectônica produziu um relevo formado por dobras, falhas e intrusões, o qual, posteriormente, nos períodos Paleo-Mesozóico, sofreu sucessivos ciclos erosivos. Esses processos erosivos denudacionais esculpiram formas de relevo predominantemente aplainadas, provavelmente, retilinizadas e colinosas. Assim, nesta superfície erosiva, após milhões de anos numa calmaria tectônica, ocorreu uma nova movimentação (Reativação Waldeniana), denominada de Sistema de Rifts da Serra do Mar (ALMEIDA, 1967) ou Rift Continental do Sudeste do Brasil (RICCOMINI, 1989), que produziu o abatimento escalonado através de falhamentos normais gerando as escarpas da Serra da Mantiqueira e da Serra do Mar. Em paralelo formou-se o Vale do Paraíba do Sul, situado sobre uma fossa ou vale tectônico, preenchido por sedimentos (HASUI e ALMEIDA, 1978). A ruptura da crosta foi relacionada a subsidência da Bacia de Santos e a área continental adjacente foi soerguida por compensação isostática (ALMEIDA e CARNEIRO, 1998).

Este esforço tectônico ocasionou um abatimento de rochas em formas de degraus, ocorrendo arqueamento nas bordas e subsidência na área central. Este processo gerou fendas por entre as rochas, as quais ocasionaram a introdução e a solidificação de magmas cooperando no levantamento da região. Após estas intrusões ígneas, as quais se formaram a partir do Cretáceo Superior ao Terciário Inferior, ocorreu a interrupção do soerguimento e então a superfície que estava sendo arqueada ficou exposta aos processos erosivos (ALMEIDA, 1964). Esta superfície de erosão é conhecida como Japi ou das Cristas Médias.

A partir do Terciário Médio dá-se uma nova pulsação tectônica e no Terciário Superior, o soerguimento tem continuidade, deformando a Superfície Japi e produzindo a arquitetura geral do relevo de toda a área. Essa arquitetura geral do relevo pode ser reconhecida em seus traços essenciais pelo exame dos altos das serranias. Ao mesmo tempo em que ocorria a movimentação tectônica e o arqueamento da superfície, ocorriam também processos de transporte e acumulação de sedimentos nas áreas de subsidência.

Nesse contexto de uma evolução lenta e contínua formou-se uma depressão tectônica, denominada de Gráben do Paraíba. Trata-se de uma bacia sedimentar continental, conhecida como Bacia de Taubaté (BJORNBERG, 1968). A Bacia de Taubaté constitui uma extensa entidade tectono-sedimentar, cujos depósitos representam ambientes e climas pretéritos que se sucederam no tempo e no espaço (AB’SABER, 1969). Ela representa o maior depósito de sedimentos do leste paulista com $170 \mathrm{~km}$ de comprimento e no máximo $20 \mathrm{~km}$ de largura, 
cobre uma extensão de $2400 \mathrm{~km}^{2}$ e atinge uma espessura máxima de pouco mais de $500 \mathrm{~m}$ (HASUI et al., 1978).

Este pacote de sedimentos é denominado como Grupo Taubaté e possui uma unidade inferior chamada de Formação Tremembé (ALMEIDA, 1967) e uma superior, Formação Caçapava (CARNEIRO et al. 1976). A Formação Tremembé é constituída principalmente por folhelhos betuminosos fossilíferos com intercalações de argilitos e de arenito. Apresenta fósseis de peixes, répteis, aves e mamíferos, entre os vertebrados; e crustáceos, moluscos e insetos, entre os invertebrados, além de palinoformos e outros restos vegetais, como folhas (MEZZALIRA \& COUTO, 1971; DNPM, 1984). Já a Formação Caçapava é afossilífera e composta por sedimentos areno-argilosos, com níveis conglomeráticos e apresenta no topo, depósitos recentes de turfa (BRANDALISE et al., 1976). A turfa, atualmente não é explorada como recurso energético e a água subterrânea possui grande potencialidade (IPT, 1978). Em algumas porções, este pacote sedimentar é encoberto por sedimentos quaternário, cujos recursos minerais consistem essencialmente de materiais de construção e de olaria, como as areias e argilas, respectivamente.

Estudos geológicos detalhados possibilitaram interpretar o paleoambiente e o paleoclima do Grupo Taubaté. Assim, a formação inferior se formou em ambiente de lagos e em condições climáticas úmidas e é contemporânea a primeira subsidência. Houve então uma fase de estabilidade tectônica, e por fim, retomada a subsidência, depositou a formação superior em ambiente fluvial e com clima sub-árido.

Esta bacia sedimentar não é uma depressão linear, mas se encontra moldada por três elevações transversais denominadas de Altos do Rio Putins, de Caçapava e de Aparecida. Na época da deposição dos sedimentos, estas elevações ocasionaram um estreitamento da espessura dos pacotes sedimentares nestas áreas e também dividiram o grande lago pretérito em quatro lagos menores, denominados de sub-bacias de Parateí/Jacareí, Eugênio de Melo, Tremembé e Lorena (HASUI \& PONÇANO, 1978). No Quaternário, os processos externos, tais como: intemperismo, movimentos de encostas, erosão e sedimentação, respondem pelo entalhamento e aperfeiçoamento das formas de relevo (RODRIGUES, 1981; FLORENZANO e CZORDAS, 1993). Assim, o Vale do Paraíba é o resultado de forças morfogenéticas de origem tectônica e climática, ou seja, a conjugação recíproca de forças endógenas e exógenas. Área de estudo

O município de São José dos Campos localiza-se a leste do Estado de São Paulo, no

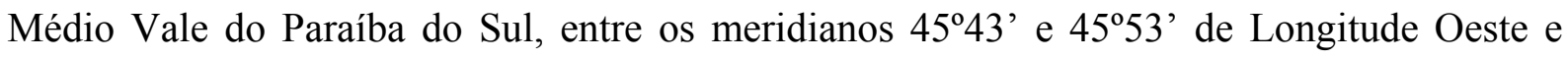
$23^{\circ} 02^{\prime}$ e $23^{\circ} 10^{\prime}$ de Latitude Sul (Figura 1), com $1.100 \mathrm{~km}^{2}$ de área total, com perímetro 


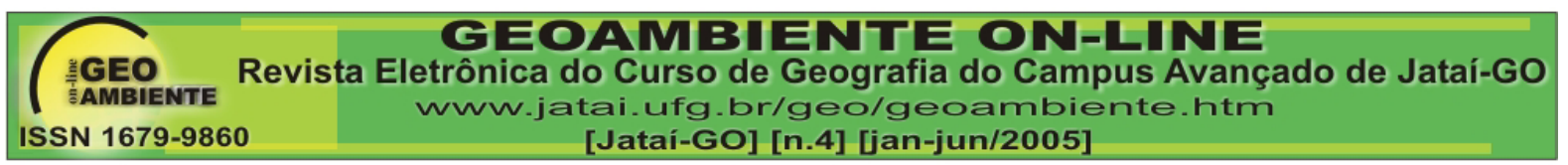

urbano de $219 \mathrm{Km}^{2}$, com uma população atual estimada em 2000 de 538.313 habitantes. A área de estudo situa-se no importante eixo Rio-São Paulo, cujo sistema viário principal é a Rodovia Presidente Dutra e está inserida na Bacia Hidrográfica do rio Paraíba do Sul, em um ambiente geotectônico, conhecido como Gráben do Paraíba ou Vale do Paraíba. Sua hidrografia tem notável importância econômica, principalmente no setor da agropecuária, alguns cursos d'água são importantes para a formação de barragens, porém, na sua maioria já estão contaminados por poluentes provenientes da atividade industrial e pela intensa urbanização.

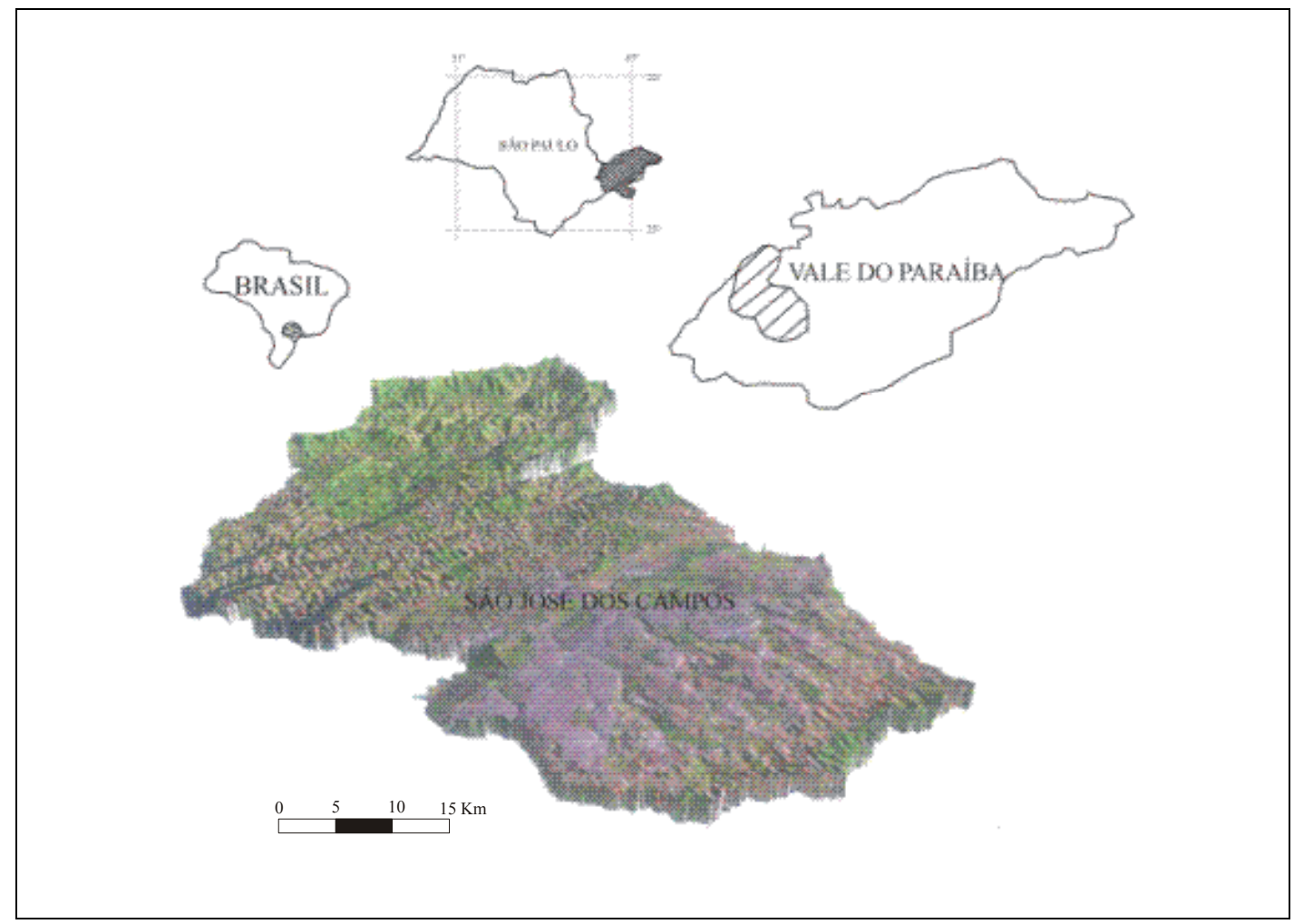

Figura 1 - Localização da área de estudo.

Da região do Vale do Paraíba, São José dos Campos destaca-se pela expansão de contingente populacional oriundos do próprio Estado e dos vizinhos. O setor comercial, impulsionado pelo crescimento econômico e populacional do município sofreu um grande aumento depois da fase industrial, que se deu com a inauguração da Rodovia Presidente Dutra, mas a partir da década de 90, a fase da terceirização, é a atividade que impulsiona o setor terciário.

O clima reinante na área é o tropical sub-quente úmido, caracterizado por um período seco de outono-inverno e um chuvoso correspondente à primavera-verão. A hidrografia está sob influência das chuvas de verão, sendo os meses de novembro a fevereiro os mais chuvosos. A gênese das chuvas é eminentemente frontal, mas o relevo apresenta importância 
como elemento orientador na distribuição regional destas. A região do vale apresenta índices pluviométricos mensais mais reduzidos que nas regiões serranas, sendo mais abundantes as chuvas na encosta voltada para o mar, ao passo que na Serra da Mantiqueira, por ser mais elevada e interior, estas proporções são menores. Além disso, na área urbana esse clima tem sofrido alterações, em razão do desmatamento e ocupação por indústrias.

Em São José dos Campos ocorrem rochas do embasamento cristalino, atribuídas aos grupos Paraíba e Açungui, nas porções norte e sul, respectivamente. Sedimentos terciários do Grupo Taubaté ocorrem ao longo da calha do rio Paraíba do Sul. A área do município situa-se no Planalto Atlântico e incluem subdivisões em domínios, determinadas por uma série de feições morfológicas distintas. Estas zonas estão representadas pela Serra da Mantiqueira, pelo Médio Vale do Paraíba e Planalto de Paraitinga.

A cobertura vegetal original de São José dos Campos era constituída por cinco diferentes tipos de formações vegetais do Domínio da Mata Atlântica e uma do Cerrado. Nos planaltos interioranos das serras do Mar e Mantiqueira ocorria a Mata Atlântica, designada tecnicamente como Floresta Estacional Semidecidual, nas escarpas das serras ocorria a Floresta Ombrófila Densa, que de acordo com a altitude são classificadas em Montana e AltoMontana. Entre estas formações, ocorria a Mata de Araucária, denominada de Floresta Ombrófila Mista e Alto-Montana. Nas colinas suavizadas ocorriam manchas de Cerrado (Savana Arbórea Aberta) e nas várzeas do rio Paraíba do Sul e de seus afluentes, as Matas de Várzeas (Floresta Estacional Semidecidual Aluvial) predominavam (MORELLI, 2002).

Com a exploração cafeeira, no início do século passado, e posteriormente as atividades pecuárias e o intenso desenvolvimento urbano e industrial ocorrido nas últimas décadas, houve uma devastação muito acentuada e rápida da cobertura vegetal original. A vegetação nativa remanescente predomina nas encostas e nas posições cumeeiras da Serra da Mantiqueira, por constituírem áreas de preservação natural. Raríssimas ocorrências também em trechos que acompanham as margens do rio Paraíba do Sul e principais tributários, constituindo-se nas denominadas matas ciliares. Nos terraços fluviais sedimentares e nas colinas ocorrem o cerrado e os campos antrópicos.

\section{Material}

Além da área de estudo, descrita no item anterior, os principais materiais necessários para a realização deste trabalho foram: a carta topográfica São José dos Campos do IBGE (folha SF-23-Y-D-II-I), escala 1:50.000; as imagens digitais TM/Landsat-5, órbita e ponto 234/76; o programa computacional SPRING (Sistema de Processamento de Informações 
Georreferenciadas; o Projeto MAVALE (Macrozoneamento do Vale do Paraíba e Litoral Norte do Estado de São Paulo; e dados coletados em campo.

\section{Metodologia}

Este trabalho, o qual teve preocupação essencialmente qualitativa, foi desenvolvido em duas fases: compilação e operacionalização de dados. A primeira fase constituiu na seleção bibliográfica (adquirir um conhecimento prévio da área de estudo), no trabalho de campo (coleta de informações adicionais) e na criação de um Banco de Dados no ambiente SPRING. Esta última visou e estruturar um modelo de dados georreferenciados para armazenar, manipular e consultar as informações geradas na próxima etapa. Assim, foi definido o modelo físico (Projeto, Categoria e Plano de Informação) no SPRING para a operacionalização neste sistema.

A segunda etapa incluiu a entrada dos dados no SPRING, a fotointerpretação das imagens TM/Landsat-5, a digitalização dos tipos de relevo e o controle de campo para a verificação e validação do produto gerado (Carta Geomorfológica do Município de São José dos Campos). A importação para o SPRING das isoípsas, dos pontos cotados e da rede de drenagem foi por digitalização manual, pois a carta topográfica se encontrava em formato analógico, via mesa digitalizadora. Estes dados foram utilizados para: definir o Sistema de Coordenadas Geográficas da área de estudo no Banco de Dados Georreferenciado (BDG); corrigir geometricamente as imagens orbitais; e elaborar o Modelo Numérico do Terreno (MNT).

As imagens TM/Landsat-5 (GeoTIFF) foram convertidas para o formato GRIB (que é o formato de armazenamento de imagens no SPRING, e em seguida foram transformadas para o Sistema de Projeção Cartográfica adotado, UTM/Córrego Alegre, para o Banco de Dados. Desta forma, o registro foi realizado pelo estabelecimento de uma relação entre sistemas de coordenadas da carta topográfica e da imagem e se baseou na presença de pontos de controle, nas junções de alguns rios com seus afluentes, que estavam bem visíveis na imagem. Foram coletados 10 pontos de controle e selecionados os cinco melhores, isto é, pontos bem distribuídos na área de estudo e que apresentavam o menor erro médio quadrático (abaixo de um pixel - menor que $30 \mathrm{~m}$ ).

A interpretação visual das imagens foi realizada pela análise da forma, tonalidade, textura, tamanho, padrão, associação e contexto e utilizando o método lógico e sistemático de fotointerpretação adaptado para imagens orbitais (VENEZIANI e ANJOS, 1982). Deste modo, foram extraídos os elementos de textura de drenagem e relevo ora utilizando a banda 4 
do TM/Landsat, ora a banda 5. Para facilitar a discriminação e a digitalização, esta etapa foi feita diretamente no monitor do computador, que permite melhorar a qualidade das imagens através de pré-processamentos de aumento de realce (ampliação de contraste) e de área (zoom). A delimitação das áreas homogêneas foi realizada por digitalização manual à medida que foram sendo identificadas no processo de interpretação. Sempre que necessário, retornouse à coleta bibliográfica e ao trabalho de campo, uma vez que constituem as fontes básicas sobre o conhecimento da área, e representam instrumentos para as soluções de problemas que naturalmente surgem na interpretação visual das imagens orbitais.

\section{Resultados e Discussões}

Foi constatado que as formas de relevo do município de São José dos Campos pertencem a três domínios geomorfológicos: formas de origem de acumulação (Planícies de Inundação, Terraços Modernos e Colinas Suavizadas); formas de origem estrutural e denudacional (Serras e Montanhas) e formas de origem denudacional (Morros Cristalinos), que podem ser vistas na Figura 2.

O domínio das formas de origem de acumulação se apresentou em áreas planas e baixas, com poucas feições estruturais e com formas de acumulação de sedimentos. O domínio de formas de origem estrutural e denudacional foi delimitado pela alta densidade de drenagem e de feições estruturais, como os planos verticais (escarpas) que evidenciam a movimentação dos blocos. No domínio das formas de origem denudacional, por ser uma área intermediária, na sua parte superior, próximos às formas de origem estrutural, predomina o processo de erosão, refletida na imagem por encostas convexo-retilíneo-côncavas. Na parte inferior, próximos às formas de origem de acumulação ocorrem processos de intemperismo, evidenciadas por encostas convexo-côncavas.

O primeiro domínio está relacionado com formas de acumulação de sedimentos de origem fluvial. Nesta área, a declividade é pequena e, conseqüentemente, apresenta-se como um amplo corredor entre as serras da Mantiqueira e do Mar e distinguem-se as seguintes feições de relevo: o leito do rio, planícies de inundação, terraços modernos e colinas suavizadas.

O rio Paraíba do Sul é meandrante, formando amplos semicírculos em áreas alagadiças. As planícies de inundação possuem níveis altimétricos entre 560 a $580 \mathrm{~m}$ de altitude, em relação ao nível do mar, e de 3 a 10 m em relação ao Rio Paraíba do Sul. Constituídas por sedimentos fluviais, cuja textura varia de argilosa a arenosa, eventualmente com cascalheiras, com porcentagem diversificada de matéria orgânica, o que possibilidade a 
ocorrência de turfas com até $11 \mathrm{~m}$ de espessura. Bordejando descontinuamente as planícies de inundação encontram-se os terraços modernos, sustentados por cascalhos e areia, eles são praticamente planos, decaindo suavemente em direção à planície. Apresentam altitudes entre 580 a 600 m em relação ao nível do mar e de 12 a 20 m em relação ao rio Paraíba. Ao sul da cidade de São José dos Campos, no limite dos terraços, ocorrem as colinas, que são em geral amplas, de encostas suavemente inclinadas e topos achatados. Elas se elevam até $650 \mathrm{~m}$ acima do nível do mar. Ao longo de drenagens formam vertentes mais abruptas entre platôs e fundos de vales. Seu substrato é constituído por sedimentos argilosos e siltosos predominantes de fácies lacustres da Formação Tremembé, em que prevalecem argilitos e folhelhos, eventualmente com camadas e lentes de arenitos. 


\section{Carta Geomorfológica do Município de São José dos Campos}

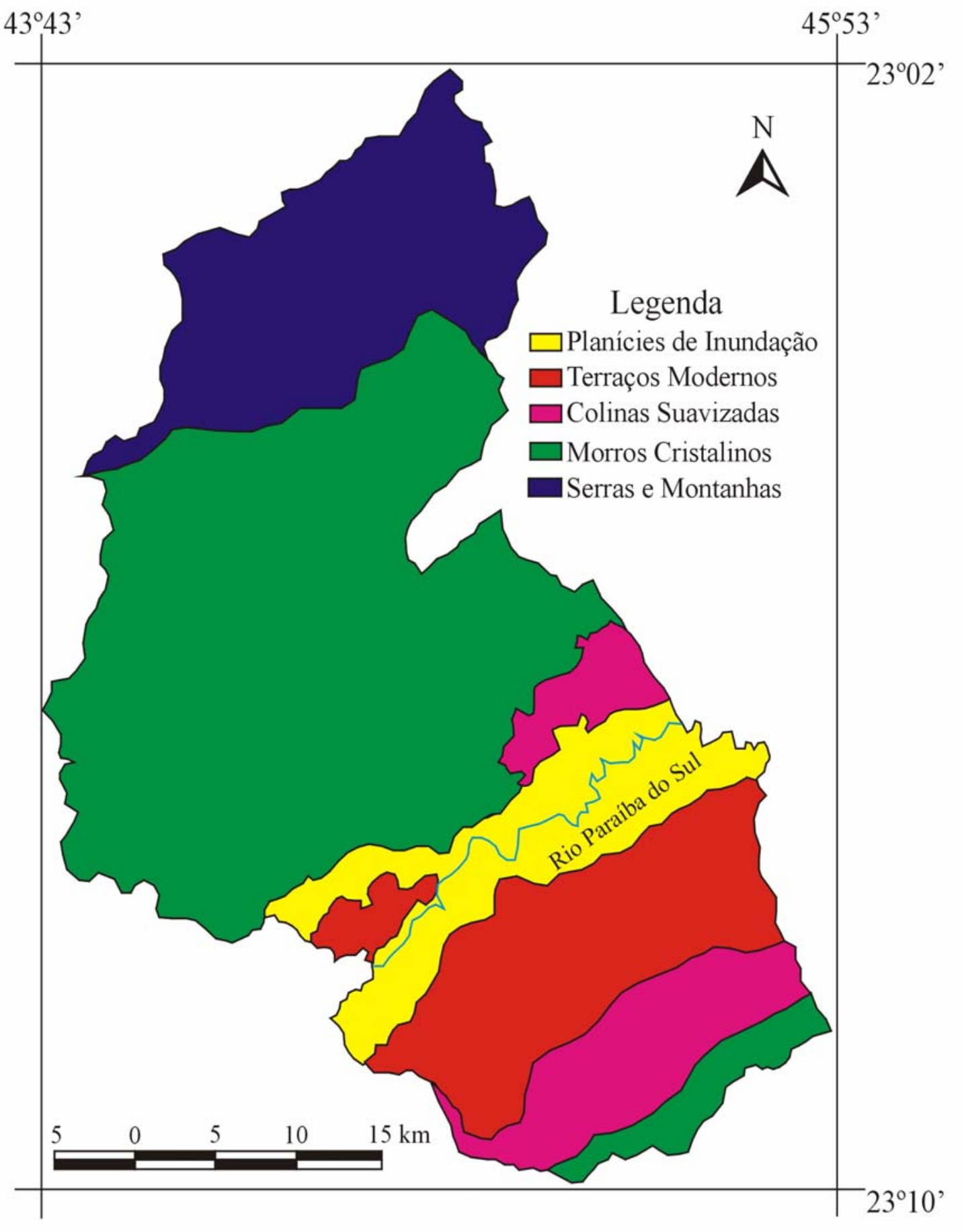

Figura 2 - Carta geomorfológica do município de São José dos Campos.

Moldurando este domínio de relevo aplainado, encontram-se os Morros Cristalinos, os quais foram formados por processos denudacionais e representam um relevo de transição da Bacia de Taubaté para o das serras da Mantiqueira e do Mar. Ocorrem na forma de relevo residual de rochas cristalinas, disperso em setores de topografia mais suave das serras e junto 
às baixadas, isolado pelos sedimentos das planícies. Apresentam substrato principalmente gnáissico e migmatítico, eventualmente granítico. As elevações dos morros têm altitudes em torno de $700 \mathrm{~m}$ e localmente alcançam $1000 \mathrm{~m}$; elas têm perfis suavizados e alturas moderadas. Os morros cristalinos, formados por rochas muito decompostas, constituem a área do domínio morfológico dos mares de morros com vertentes convexas, tidas como produtos de forte atividade de uma morfogênese química e biogênica em consonância com as condições climáticas vigentes.

O terceiro domínio é representado pelas serras e montanhas, as quais caracterizam-se por cotas que podem ultrapassam os 1.100 m no município de São José dos Campos. O relevo mostra-se muito jovem, reflexo da tectônica moderna que agiu sobre a região. As escarpas da Serra da Mantiqueira são compostas por encostas localizadas ao norte do município, em sistemas de relevo constituídos por serras restritas e alongadas e montanhas com encostas e depressões em forma de anfiteatros. Seu escarpamento apresenta-se bastante abrupto, evidenciando o estágio imaturo de sua evolução geomorfológica. Nesta faixa, os processos denudacionais e tectônicos são responsáveis pela esculturação do relevo.

A malha urbana do município assenta-se quase que totalmente em áreas baixas, relativamente planas a levemente onduladas dos terraços modernos e colinas suavizadas (Figura 3), as quais apresentam menores riscos geológicos, ou seja, apresentam maiores capacidades de suporte da apropriação do território e menores custos operacionais na construção urbana, pois evitam grandes investimentos geotécnicos. Deste modo, nos primórdios do surgimento da cidade de São José dos Campos, foram atendidas às necessidades humanas sem negligenciar as possibilidades oferecidas pelo sistema morfológico. 

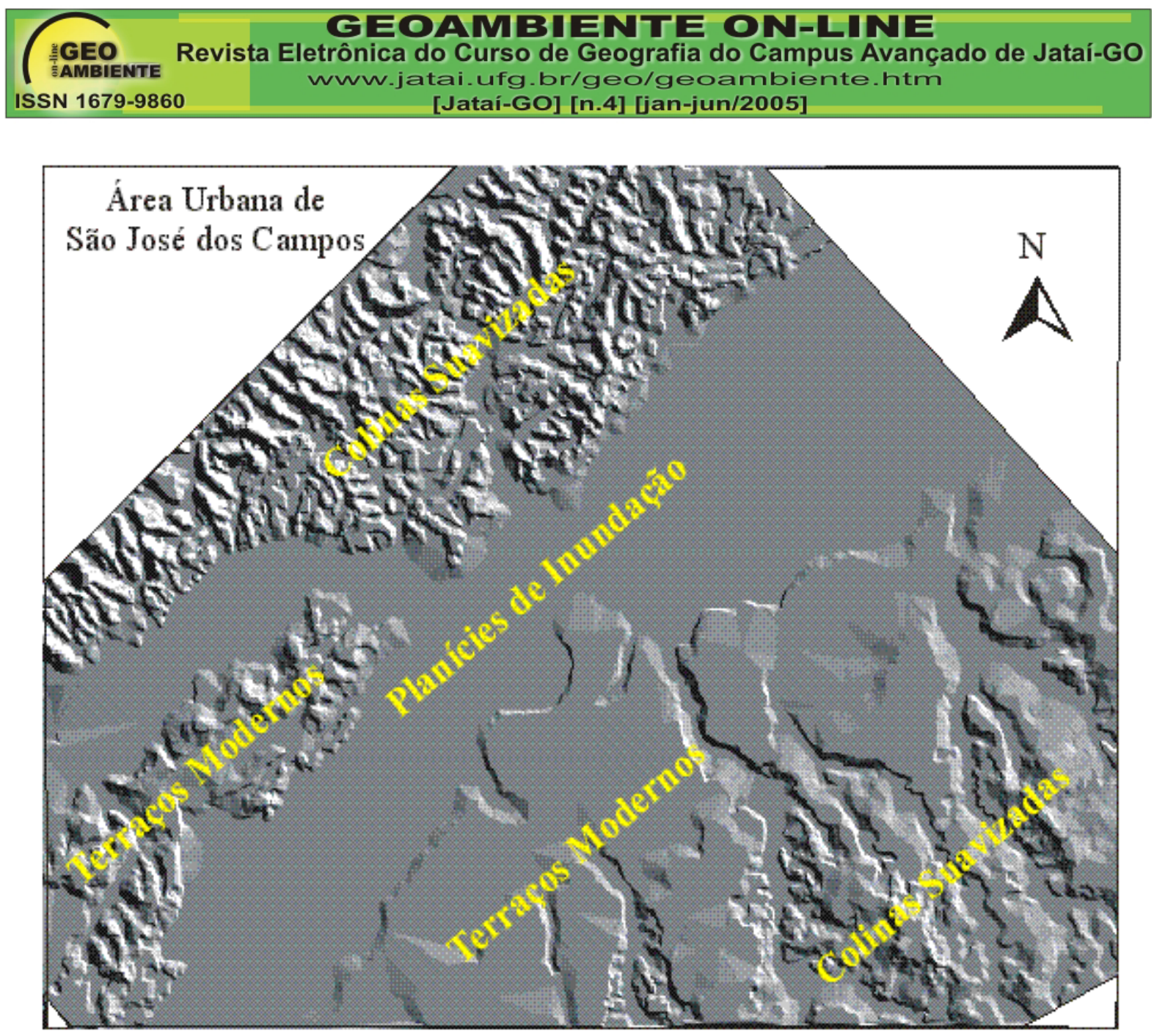

Figura 3 - Modelo Numérico do Terreno mostrando os tipos de relevo, que concentram a malha urbana de São José dos Campos.

\section{Considerações finais}

O relevo do município de São José dos Campos é caracterizado por formas de acumulação de origem fluvial, constituído por colinas aplainadas, terraços modernos e planície de inundação; por formas de origem estrutural/denudacional, formadas por escarpas abruptas, com grandes desníveis, evidenciando estágio imaturo de sua evolução. Entre estes dois domínios geomorfológicos encontram-se feições intermediárias de formas denudacionais representadas por morros cristalinos, com boçorocas se manifestando por toda a área.

O processo de urbanização se deu nas áreas mais favoráveis, isto é, com menores riscos à ocupação, onde o relevo foi incorporado naturalmente como determinante das derivações espaciais, e foi o indicador de maior ou menor fragilidade do ambiente, sujeito à intervenção humana. Assim, foi nesta perspectiva que a construção do meio urbano se deu consorciada as formas de relevo. Como conseqüência, esta construção do urbano foi a ótica do planejamento, norteador por primar a qualidade ambiental e de vida das pessoas. 


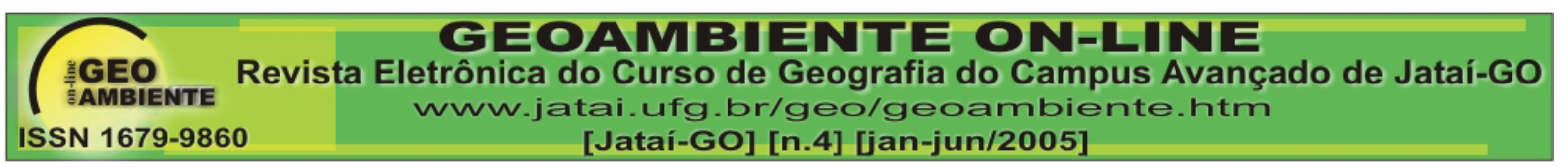

No entanto, uma menor área urbana atinge as planícies de inundação e as porções mais elevadas, estas últimas não estão apresentadas na figura 3. Nestas duas áreas, os processos naturais que ocasionam acidentes são altos e se aceleram com as edificações. Assim, a suscetibilidade à enchentes, inundações, subsidência e colapso de solos, erosão e escorregamentos e processos correlatos é alta. Estes processos provocam rachaduras nas construções devido ao peso dessas obras nos sedimentos arenosos inconsolidados das planícies de inundação, e perdas de casas e vidas pelas enchentes e soterramentos nos vales fluviais várzeas e pelos movimentos de massa nas encostas íngremes.

Nota-se que, a temporalidade do cenário natural tem conflitado com a temporalidade sócio-cultural, que cada vez mais altera a paisagem, mediada pela técnica e pela ciência ou não. A análise do cenário urbano atual revela a forma desordenada de apropriação do relevo nos dias atuais, que se encontra crescente nos vales fluviais, sobre o leito dos cursos de drenagem e nas encostas íngremes.

\section{Referências bibliográficas}

AB'SABER, A. N. O Quaternário da Bacia de Taubaté: estado atual dos conhecimentos. Geomorfologia. São Paulo, v.7, p.52-54, 1969.

ALMEIDA, F. F. M. Fundamentos geológicos do relevo paulista. Boletim, Instituto Geográfico e Geológico. São Paulo. v. 41. p.167-263,1964.

ALMEIDA, F. F. M. Origem e evolução da plataforma brasileira. Rio de Janeiro, DNPM/DGM, 1967. 241p.

ALMEIDA, F. F. M. e CARNEIRO, C. D. R. Origem e evolução da Serra do Mar. Rev. Bras. de Geociências. São Paulo: SBG, v.28, n.2, p.135-150. 1998.

BJORNBERG, A. J. S. Contribuição ao estudo da Bacia de Resende. Boletim da Sociedade Brasileira de Geologia. Rio de Janeiro. v. 17, n. 11, p. 65-74. 1968.

BRANDAliSE, L. A.; RIBEIRO, J. H.; FERRARI, P. G. Projeto Vale do Paraíba do Sul: relatório final. DNPM/CPRM. Belo Horizonte, 1976.

CARNEIRO, C. D. R.; HASUI, Y.; GIANCURSI, F. D. Estrutura da Bacia na região de São José dos Campos. In: congresso Brasileiro de Geologia, 29.,Ouro Preto, 1976. Anais... Ouro Preto, v.1. p. 105-110.

DNPM (Departamento Nacional de Produção Mineral). Geologia do Brasil., DNPM/DGM, 1984. 501p. 
FLORENZANO, T. G. Unidades geomorfológicas da região Sudeste (SP) identificados por imagens de satélites. 1993. 164f. Tese (Doutorado em Geografia) - Faculdade de Filosofia, Letras e Ciências Humanas.Universidade Estadual Paulista, São Paulo.

FLORENZANO, T. G.; CZORDAS, S. M. Mapa geomorfológico da região do Vale do Paraíba e litoral norte do estado de São Paulo. São José dos Campos: INPE, 1993, 15p. (INPE-5531-PRP/179).

IPT (Instituto de Pesquisas Tecnológicas). Geologia da folha de São José dos Campos. São Paulo, IPT, 1978, v.1.

HASUI, Y.; ALMEIDA, F. F. M. Aspectos estruturais na geomorfologia da área cristalina de São Paulo e Paraná. In: Congresso Brasileiro de Geologia, 30., Recife, 1978. Anais... Recife, v.1, p. 360-367.

HASUI, Y.; PONÇANO, W. L. Organização estrutural e evolução da bacia de Taubaté. In: Congresso Brasileiro de Geologia, 30., Recife, 1978. Anais... Recife, p. 368-381, v.1.

HASUI, Y.; PONÇANO, W. L.; BISTRICHI, C. A.; Stern, D. P.; Galvão, C. A. C. F.; GIMENES, A. F.; ALMEIDA, M. A.; SANTOS, M. C. S R. Geologia da região administrativa 3 (Vale do Paraíba) e parte da região administrativa 2 (Litoral) do Estado de São Paulo. São Paulo, IPT, 1978. 1106p.

MEZZALIRA, S.; COUTO, C. P. Nova conceituação geocronológica de Tremembé, Estado de São Paulo. Anais da Academia Brasileira de Ciências, v. 43, p. 473-488, 1971. Suplemento.

MORELLI, A. F. Identificação e transformação das unidades da paisagem no município de São José dos Campos (SP) de 1500 a 2000. 2002. 408f. Tese (Doutorado em Geociências e Meio Ambiente) - Instituto de Geociências e Ciências Exatas. Universidade Estadual Paulista. Rio Claro.

OLIVEIRA, A. B. Análise geomorfológica e sócio-econômica como instrumento de ação no planejamento urbano. 1997. 204f. Dissertação (Mestrado em Geociências e Meio Ambiente) Instituto de Geociências e Meio Ambiente Exatas. Universidade Estadual Paulista. Rio Claro. RICCOMINI, C. O Rift Continental do Sudeste do Brasil. 1989. 256f. Tese (Doutorado em Geologia). - Instituto de Geociências. Universidade de São Paulo. São Paulo.

RODRIGUES, J. P. Aplicação de sensoriamento remoto no mapeamento fotogeológico da região do complexo alcalino de Itatiaia. 1981. 166f. Dissertação (Mestrado em Sensoriamento Remoto) - Instituto Nacional de Pesquisas Espaciais. São José dos Campos.

VENEZIANI, P.; ANJOS, C. E. Metodologia de interpretação de dados de sensoriamento remoto e aplicações em geologia. São José dos Campos: INPE, 1982. 54p. 